\title{
Characterization of the Cdc6 Homologues from the Euryarchaeon Thermoplasma acidophilum
}

\author{
Gyri Teien Haugland*,1, Marte Innselset ${ }^{2}$, Dominique Madern ${ }^{3}$ and Nils-Kåre Birkeland ${ }^{1}$ \\ ${ }^{I}$ Department of Biology, University of Bergen, P.O. Box 7800, N-5020 Bergen, Norway \\ ${ }^{2}$ Department of Biomedicine, University of Bergen, Jonas Lies Vei 91, N-5009 Bergen, Norway \\ ${ }^{3}$ Institute of Structural Biology, CEA-CNRS-UJF, 41 Rue Jules Horowitz, 38027 Grenoble, France
}

\begin{abstract}
Archaeal cell division cycle protein 6 (Cdc6) homologues are thought to be involved in the initiation process of DNA replication. In the present study, a biochemical characterization of the two Cdc6 proteins from the archaeon Thermoplasma acidophilum has been performed. Both TaCdc6-1 and TaCdc6-2 behave as monomers in solution and both are abundantly expressed in vivo. Further, TaCdc6-1 shows strong ability to undergo autophosphorylation compared to TaCdc6-2 and the autophosphorylation activity is not affected by DNA or MCM.
\end{abstract}

\section{INTRODUCTION}

In archaea, homologues to eukaryotic Cdc6 proteins are thought to be involved in origin recognition and loading of the replicative DNA helicase prior to DNA replication (reviewed in $[1,2])$. The Cdc6 proteins are members of the $\mathrm{AAA}^{+}$(ATPases associated with various cellular activities) family [3] and crystal structures have shown that they have a $\mathrm{N}$-terminal ATP binding module consisting of two domains and a C-terminal winged-helix (WH) domain [4-7]. The Cdc6 proteins and other initiation proteins are called $\mathrm{AAA}^{+}$ switches due to their ability to alter their structure and function depending on the resident nucleotide, and thus, the most important mode of regulating the DNA replication is through nucleotide binding and hydrolysis (reviewed in $[2,8]$ ).

All archaeal Cdc6 proteins studied to date have shown the ability to undergo autophosphorylation and it has been suggested that autophosphorylation might play a regulatory role during the initiation process [9]. In addition to autophosphorylation, archaeal Cdc6 proteins are able to bind both single-stranded (ss) and double-stranded (ds) DNA and some Cdc6 proteins bind specifically to origin of replication (reviewed in $[1,2]$ ). Although the archaeal Cdc6 proteins are monomers in solution, co-crystallization of the proteins with inverted DNA repeats found within the archaeal origins of replication and footprinting analysis, have shown that they interact with origin DNA as dimers $[4,10]$.

Thermoplasma acidophilum is a thermoacidophilic euryarchaeon encoding two putative Cdc6 homologues (TaCdc6-1 and -2) and one putative minichromosome maintenance (MCM) homologue, TaMCM. Previous studies have shown that TaCdc6-2, but not TaCdc6-1, interacts with TaMCM and stimulates its helicase activity $[11,12]$. The work presented here is a study on the TaCdc6 homologues, including size determination, in vivo levels of expression and their ability to autophosphorylate.

*Address correspondence to this author at the Department of Biology, University of Bergen, P.O. Box 7800, N-5020 Bergen, Norway; Tel: +47 55584882; Fax: +47 55589671; E-mail: Gyri.Haugland@ bio.uib.no

\section{MATERIALS AND METHODS}

\section{Cloning and Protein Purification}

The pET21a - constructs with Ta0451m (encoding TaCdc6-1) and Ta0636 (encoding TaCdc6-2) were made as described previously [11]. The recombinant proteins were over-expressed in Escherichia coli BL21-CodonPlus (DE3) RIL cells (Stratagene) using ZYP-5052 medium according to Studier's method for auto-induction [13] and purified as described previously [11] .

\section{Gel Filtration}

For molecular mass determination $72 \mu \mathrm{g}$ of each of the purified TaCdc6 proteins were applied to a superdex 200 gel-filtration column (HR10/30; GE Healthcare) preequilibrated with buffer A containing $20 \mathrm{mM}$ Tris-HCl, $\mathrm{pH}$ $7.5,100 \mathrm{mM} \mathrm{NaCl}$ and $10 \%$ glycerol. The gel filtration experiments were performed at $22^{\circ} \mathrm{C}$ with a flow rate of 0.5 $\mathrm{ml} / \mathrm{min}$.

\section{Sedimentation Velocity Measurement}

Sedimentation velocity experiments were done on a Beckman XLI analytical ultracentrifuge, equipped with a UV scanning system, using a four holes AN-60 Ti rotor with double-channel centrepieces of $1.2 \mathrm{~cm}$ optical path-length. The protein sample $(0.25 \mathrm{mg} / \mathrm{ml})$ was in buffer B containing $50 \mathrm{mM}$ Tris, $\mathrm{pH}$ 8.0. Two hundred absorbance profiles at $280 \mathrm{~nm}$ for each sample were recorded at 42,000 RPM at $20^{\circ} \mathrm{C}$. The experimental sedimentation coefficients were determined using the Sedfit software [14].

\section{Autophosphorylation}

Protein autophosphorylation activity was measured in reaction mixtures $(15 \mu \mathrm{l})$ containing $20 \mathrm{mM}$ Hepes- $\mathrm{NaOH}$, $\mathrm{pH} 7.5,5 \mathrm{mM} \mathrm{MgCl} 2,2 \mathrm{mM}$ DTT, $450 \mathrm{ng} \mathrm{BSA}, 3.3$ pmol of $\left[\gamma^{32}\right.$ P]ATP (GE Bioscience), 10 pmol TaCdc6 proteins with or without $1 \mu \mathrm{g}$ ssDNA ( $\phi$ X174 virion DNA; New England Biolabs) or dsDNA ( $\phi$ X174 RFII DNA; New England Biolabs) and with or without 20 pmol TaMCM as indicated in the figure legends. Following incubation at $58^{\circ} \mathrm{C}$ for $20 \mathrm{~min}$, 
the reaction was stopped by adding $5 \mu 1$ of $5 \mathrm{x}$ SDS loading buffer (250 mM Tris-HCl, pH 6.8, 500 mM DTT, 10\% SDS, $0.5 \%$ Bromophenol blue and $50 \%$ glycerol). The reaction mixtures were boiled for $5 \mathrm{~min}$ and subsequently separated by $12 \%$ SDS-PAGE performed at $190 \mathrm{~V}$ for $60 \mathrm{~min}$ and stained with Coomassie blue. The gel was dried and ${ }^{32} \mathrm{P}-$ labeled bands were detected using phosphorimaging. The experiments were repeated three times. A representative gel and autoradiograph is shown in Fig. (4A and $B$ ).

\section{Cultivation of Thermoplasma Acidophilum}

T. acidophilum (DSM 1728) were grown in DSMZ medium 158 (http://www.dsmz.de/microorganisms/html/media/ medium000158.html), $\mathrm{pH} 1.9$ at $55^{\circ} \mathrm{C}$ with shaking and the cells were harvested in exponential phase. The growth was monitored by OD measurements at $600 \mathrm{~nm}$ and cell counts as indicated in Fig. (3A).

\section{Quantification of TaCdc6 Proteins Using Western Blot Analysis}

Purified, recombinant TaCdc6 proteins and cell extract from $T$. acidophilum were fractionated using 12\% SDSPAGE, followed by electro-blotting onto a nitrocellulose membrane. Western blot analyses were performed using TaCdc6-1 and TaCdc6-2 polyclonal antibodies generated against the recombinant proteins by BioGenes $\mathrm{GmbH}$ (Germany), and developed using enhanced chemiluminescent (ECL, GE Healthcare). The bands were quantified using Image $\mathrm{J}$ [15].

\section{Modeling}

The models of TaCdc6-1 and TaCdc6-2 were generated by automated homology modeling using Deepview/SwissPdbViewer v3.7 [16,17]. The FASTA sequence of TaCdc6-1 was fitted to $1 \mathrm{FNN}$, the crystal structure of Cdc6 from Pyrobaculum aerophilum (PaCdc6) [6], suggested as template using the "magic fit" application of the program, while TaCdc6-2 was fitted to 2QBY which is the structure of Cdc6 from Sulfolobus solfataricus [4]. The resulting preliminary alignment was manually adjusted to align residues corresponding to the active site and other conserved areas based on ClustalW2 [18] alignment before submission to SwissModel Automated Comparative Protein Modeling Server (http://swissmodel.expasy.org/) [16,17,19].

\section{RESULTS AND DISCUSSION}

\section{The TaCdc6 Proteins are Monomers in Solution}

Purified TaCdc6 proteins (Fig. 1) were analyzed by gel filtration for mass determination. TaCdc6-1 eluted at $14.3 \mathrm{ml}$ which corresponds to a monomer having a theoretical molecular mass of $42 \mathrm{kDa}$ (Fig. 2A). TaCdc6-2 was expected to elute at approximately the same volume as it has similar theoretical molecular mass $(46.5 \mathrm{kDa})$. TaCdc6-2 did, however, elute at $13.2 \mathrm{ml}$, the same volume as albumin which has a molecular mass of $67 \mathrm{kDa}$ (Fig. 2B). A limitation of gel filtration as a method for molecular mass determination is that it does not account for shape and hydration of proteins and thus, the method will work well only if the protein of interest has a spherical symmetrical shape and an average hydration level [20]. The behavior of TaCdc6-2 was thus investigated using analytical ultracentrifugation in order to monitor the oligomeric state and shape of the protein. Under the conditions described in "Materials and Methods", the theoretical value of a globular monomeric TaCdc6-2 is $3.7 \mathrm{~S}$. The experimental sedimentation profiles were analyzed using the continuous $\mathrm{c}(\mathrm{s})$ distribution model with bimodal frictional coefficient (f/fo) in the sedfit program. The data were well fitted by a mixture of globular $(50 \%)$ and extended $(50 \%)$ monomeric forms without dimer (data not shown). The globular monomeric form $(\mathrm{f} / \mathrm{f0}=1.25)$ has an experimental s value of $3.6 \mathrm{~S}$, i.e. close to the theoretical value. The second form has a lower s value of $2 \mathrm{~S}$ and a frictional coefficient $\mathrm{f} / \mathrm{f} 0=1.5$ showing that the monomer also exists in an extended shape. The equilibrium between the extended and globular forms explains the TaCdc6-2 retardation using the gel filtration column. The results agree with previous studies reporting that archaeal Cdc6 proteins are monomers [6,7,21-23]. However, X-ray diffraction crystallography has shown that the Cdc6-1 and -3 homologues in Sulfolobus solfataricus (SsCdc6-1 and -3) form a hetero-complex at the origin of replication [4]. Whether this is the situation in $T$. acidophilum and other archaea remains to be determined.

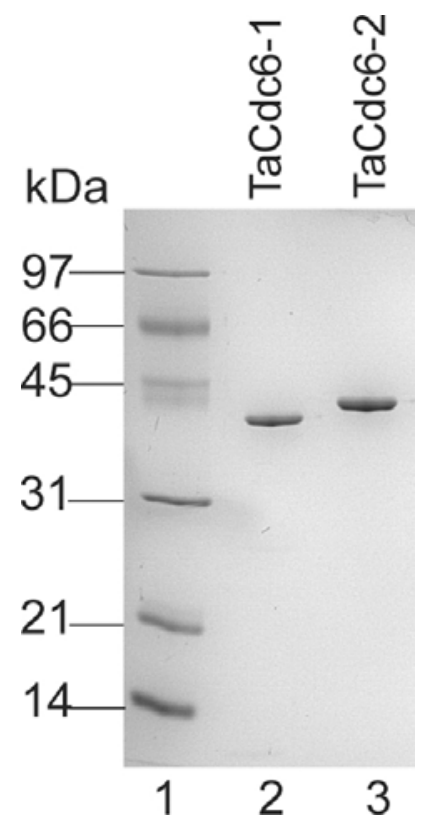

Fig. (1). Purified proteins used in this study.

Aliquots $(0.5 \mu \mathrm{g})$ of each of the purified TaCdc6 proteins were fractionated on a $12 \%$ SDS-PAGE gel and visualized by Coomassie blue staining. Lane 1: molecular mass marker; lane 2, T. acidophilum Cdc6-1; lane 3, T. acidophilum Cdc6-2.

\section{TaCdc6-1 and TaCdc6-2 are Abundantly Expressed in Thermoplasma Cells.}

In order to verify the expression of the putative TaCdc6 homologues in vivo, polyclonal antibodies against recombinant TaCdc6-1 and TaCdc6-2 were raised in rabbits. Western blot analyses of a cell extract of $T$. acidophilum revealed specific bands corresponding to similar molecular mass as the recombinant proteins, indicating that both proteins are indeed expressed in vivo. A quantitative Western analysis was subsequently performed in order to determine the number of the TaCdc6 proteins per cell during exponential growth phase. The intensities of bands corresponding to 

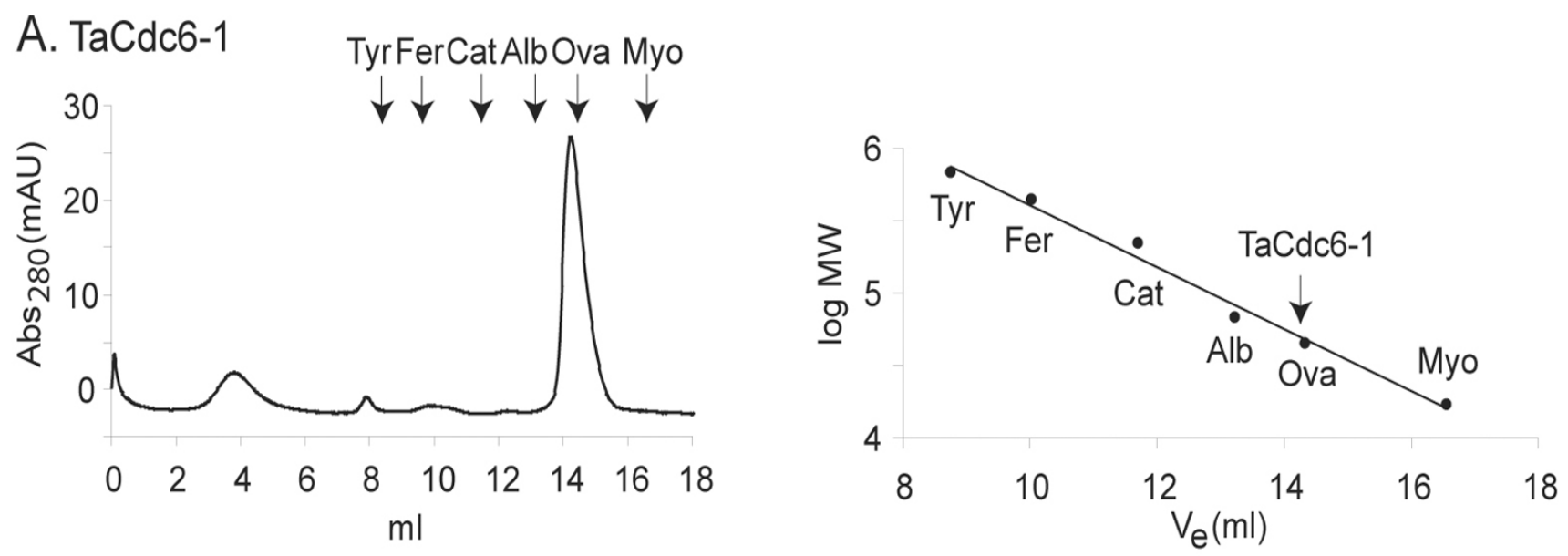

\section{B. TaCdc6-2}
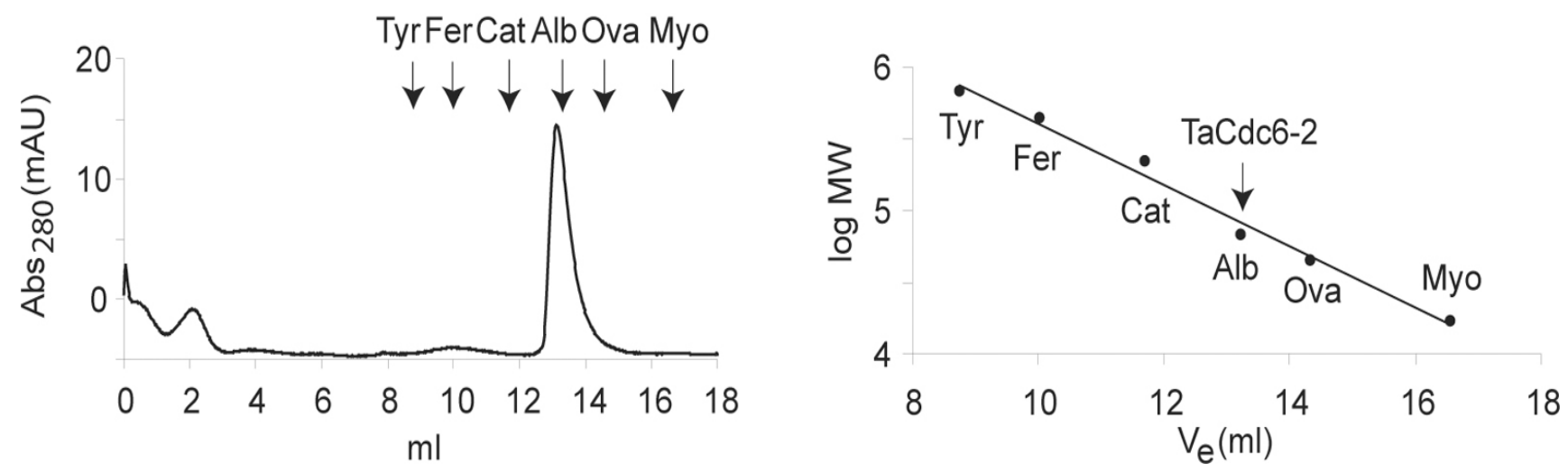

Fig. (2). T. acidophilum Cdc6 proteins are monomers in solution.

A. Gel filtration chromatography of TaCdc6-1 was performed as described in "Materials and Methods". The peak elution volumes of thyroglobulin (Tyr, $670 \mathrm{kDa}, 8.76 \mathrm{ml}$ ), ferritin $(440 \mathrm{kDa}, 10.02 \mathrm{ml})$, catalase (Cat, $232 \mathrm{kDa}, 11.7 \mathrm{ml})$, albumin (Alb, $67 \mathrm{kDa}, 13.22 \mathrm{ml})$, ovalbumin (Ova, $45 \mathrm{kDa}, 14.34 \mathrm{ml}$ ) and myoglobulin (Myo, $13 \mathrm{kDa}, 16.56)$ are shown in the elution profile of TaCdc6-1 (upper panel) and used to make a calibration curve (lower panel). The arrow indicates the position of the TaCdc6-1 protein.

B. Gel filtration chromatography of TaCdc6-2. The position of molecular marker proteins is shown as described in A. The arrow indicates the position of the TaCdc6-2 protein.

varying numbers of Thermoplasma cells were compared with different molar amounts of recombinant TaCdc6 proteins (Fig. 3B and C), suggesting the presence of 3000 4000 molecules per cell of each of the two TaCdc6 proteins. This is in agreement with observations from other archaea $[21,24]$. The reason for the large number of Cdc6 proteins in archaea is currently unknown, but it is suggested that the Cdc6 proteins may have other functions in the cell in addition to regulation of DNA replication. For example, studies of $S$. solfataricus have shown that the transcription of SsCdc6-2, but not SsCdc6-1 and -3, was highly induced in UV treated cells, implicating a function in DNA repair $[25,26]$.

\section{The TaCde6 Homologues are Able to Undergo Auto- phosphorylation}

Both TaCdc6-1 and TaCdc6-2 contain conserved AAA ${ }^{+}$ motifs as well as winged-helix (WH) motifs as shown by sequence comparison analysis. Also, models of TaCdc6-1 and -2 three-dimensional structures were constructed, and as expected, both were similar to other Cdc6 proteins (data not shown). As both proteins belong to the AAA+ family, AT-
Pase activity was expected. However, only weak ATPase activity was observed (data not shown). This is similar to other archaeal and eukaryotic Cdc6 proteins [9,21,27].

The ATPase activity of Cdc6 proteins can, however, also be indirectly shown by their ability to autophosphorylate. This is because the proteins have to bind ATP and break the interaction between the $\beta$ - and $\gamma$-phosphate prior to phosphorylation [9]. To investigate whether the TaCdc6 proteins are able to autophosphorylate, the proteins were incubated at $58^{\circ} \mathrm{C}$ as described in "Materials and Methods" in the presence of $\left[\gamma^{32} \mathrm{P}\right] \mathrm{ATP}$. As shown in Fig. (4A) (lane 2 and 5), TaCdc6-1 undergoes stronger autophosphorylation than TaCdc6-2. Although both proteins show ability to autophosphorylate, the level of autophosphorylation is low. In other archaeal Cdc6 the level of phosphorylation was measured to be less than $1 \%$ [9].

Previous studies with Methanothermobacter thermautotrophicus, have shown that DNA affects the Cdc6 autophosphorylation [9]. However, as shown in Fig. (4A) (lane 2 versus lane 3-4 and lane 5 versus 6-7), the activity of the TaCdc6 proteins is not significantly affected by DNA. This 
B. TaCdc6-1

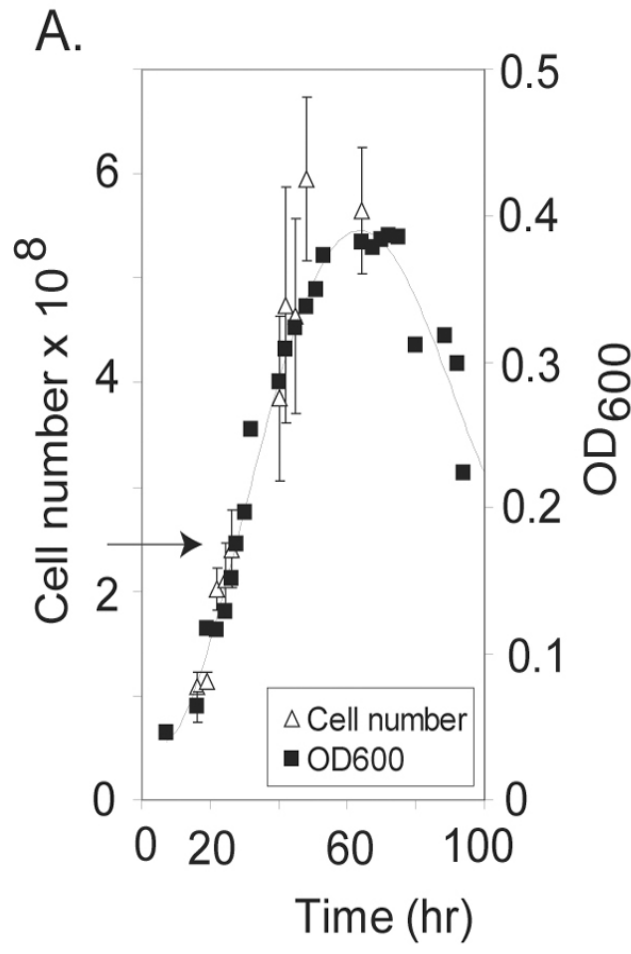

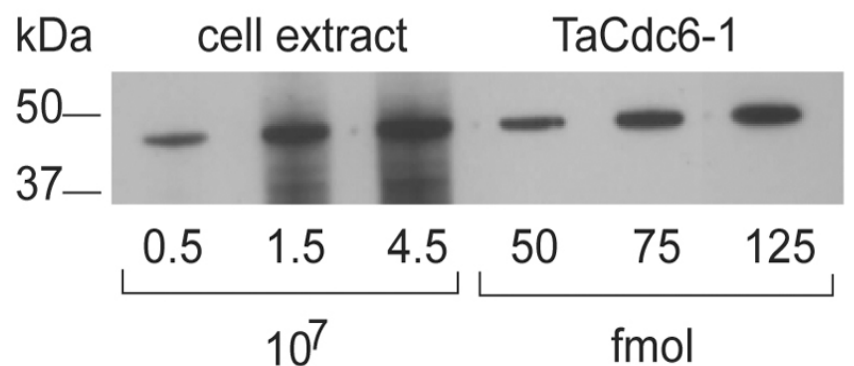

C. TaCdc6-2

$\mathrm{kDa} \quad$ cell extract TaCdc6-2

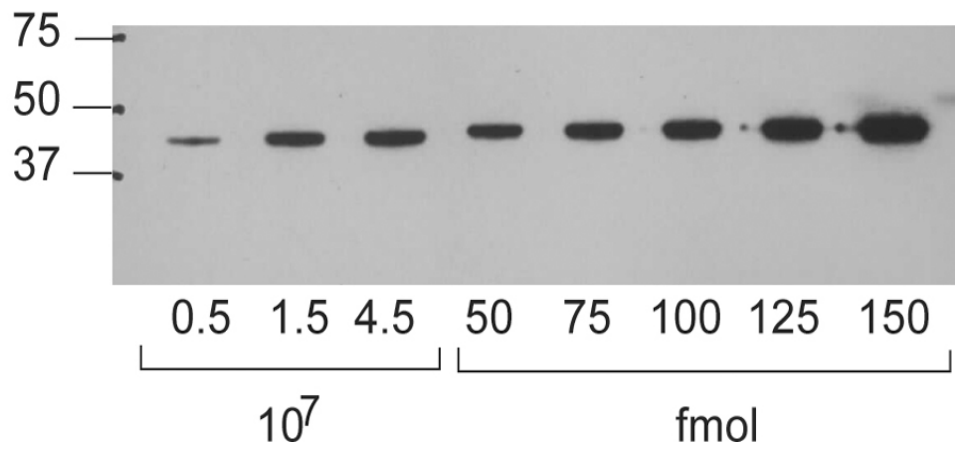

Fig. (3). T. acidophilum Cdc6-1 and -2 is abundantly expressed in vivo during exponential growth phase.

A. Growth curve of $T$. acidophilum. The number of cells $\left(10^{8}\right)$ and density $\left(\mathrm{OD}_{600}\right)$ are plotted versus time (hours). The arrow indicates the time of harvesting.

B. Quantitative Western blot of TaCdc6-1 in T. acidophilum was performed as described in "Materials and Methods". T. acidophilum extract corresponding to a certain number of cells $\left(\mathrm{x} 10^{7}\right)$ and amount of purified, recombinant TaCdc6-1 protein (fmol) loaded onto each lane are indicated.

C. Quantitation of TaCdc6-2 in T. acidophilum cells was performed as described in B.

is similar to the Cdc6 homologues in S. solfataricus, suggesting that the regulation of autophosphorylation varies within the archaeal domain.

Both archaeal Cdc6 and MCM proteins are suggested to be involved in initiation of DNA replication and studies have shown that the proteins affect each others biological activities (review in $[1,2]$ ). Thus, the effect of the TaMCM on TaCdc6 autophosphorylation was analyzed. A TaMCM mutant, $\mathrm{K}_{343} \mathrm{~A}$, where lysine in the conserved Walker-A motif has been replaced by alanine, is devoid of ATPase activity [11] and used in this experiment as ATP hydrolysis by MCM would limit the available ATP. Otherwise, the TaMCM wildtype and $\mathrm{K}_{343} \mathrm{~A}$ mutant are similar and both interact with TaCdc6-2 [11,12]. As shown in Fig. (4B) (lane 3 versus 4 and lane 5 versus 6), TaMCM did not significantly affect the TaCdc6 autophosphorylation activity. This is different from studies with $M$. thermautotrophicus where the Cdc6-MCM interaction modulates the autophosphorylation activity of the Cdc6 proteins [28].

All archaeal Cdc6 proteins studied have shown the ability to autophosphorylate. The in vivo function of autophosphorylation is not yet known, but it has been suggested that phosphorylation might play a regulatory role during the initiation process. This regulation might either be positive, allowing Cdc6 binding to origins, or negative, preventing rebinding of Cdc6 to the origins once the helicase is loaded into DNA $[9,29]$. A mechanism of preventing re-replication (re-initiation of a recently activated origin within the same cell cycle) in eukaryotes is to limit the accessibility of initiation proteins by protein phosphorylation, and thereby "labeling" the proteins for degradation or export out of the nucleus. In this context it has been suggested that autophosphorylation might be a mechanism to prevent re-replication in archaea [29].

In addition to possessing different biochemical properties, as reported here and in a previous study [11], TaCdc6-1 and TaCdc6-2 belong to different subgroups of Cdc6 [7,30]. It is thus tempting to speculate whether the two Cdc6 homologues have separate roles during the initiation of DNA replication in T. acidophilum. However, further analysis such as DNA binding is needed to address this question.

\section{ACKNOWLEDGEMENT}

We would like to thank Dr. Zvi Kelman for his support and encouragement during the course of this work and Marit 


\section{A. Effect of DNA}

\section{SDS-PAGE}
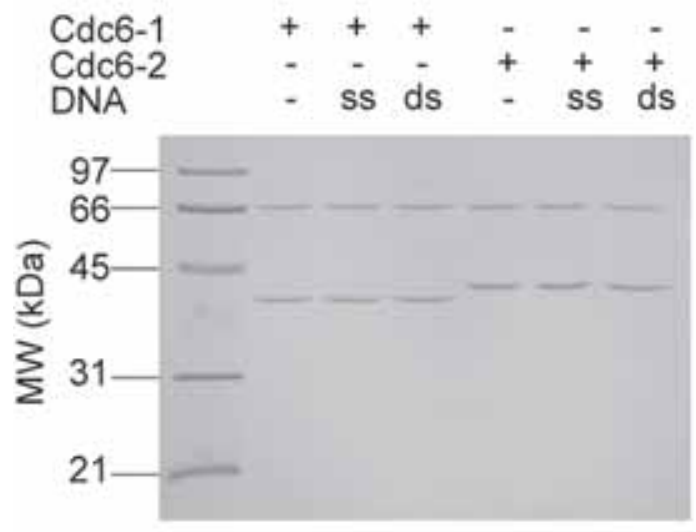

AUTORADIOGRAM

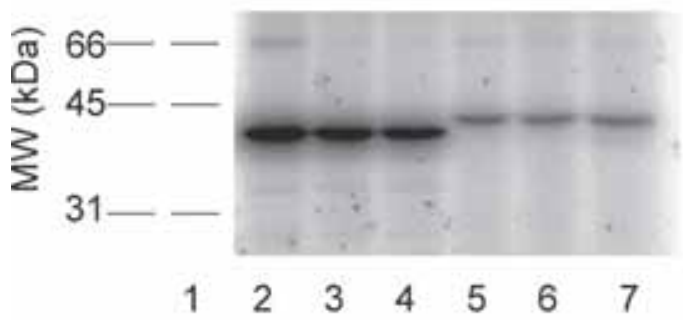

B. Effect of TaMCM SDS-PAGE

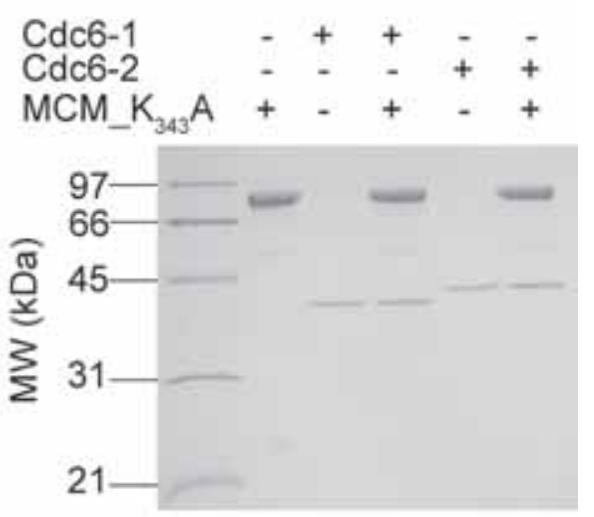

AUTORADIOGRAM

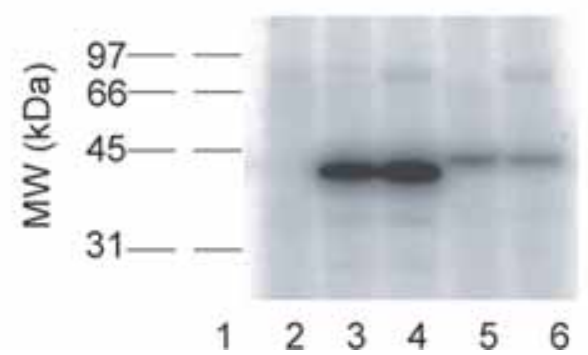

Fig. (4). The autophosphorylation activity of T. acidophilum Cdc6 is not affected by DNA or MCM.

A. The activity of TaCdc6 is not affected by DNA. Cdc6 autophosphorylation reactions were performed as described in "Materials and Methods" in a reaction mixture $(15 \mu \mathrm{l})$ containing 10 pmol Cdc6 protein in the absence (lane 2 and 5) or in the presence of $1 \mu \mathrm{g}$ ssDNA (lane 3 and 6) or $1 \mu \mathrm{g}$ dsDNA ((lane 4 and 7). Upper panel shows a representative 12\% Coomassie stained SDS-polyacrylamide gel. Lower panel shows a representative autoradiogram.

B. Cdc6 autophosphorylation reactions were performed as described in "Materials and Methods" in a reaction mixture (15 $\mu 1)$ containing 10 pmol Cdc6 protein in the absence (lane 3 and 5) or presence of 20 pmol MCM (lane 4 and 6). Upper panel shows a representative 12\% Coomassie stained SDS-polyacrylamide gel. Lower panel shows a representative autoradiogram.

S. Madsen for help with culturing Thermoplasma acidophilum. This work was supported by a grant from the Norwegian Research Council (no. 153621/V40) awarded to NKB and a grant from the National Science Foundation (MCB0815646) awarded to Zvi Kelman.

\section{REFERENCES}

[1] Barry, E.R.; Bell, S.D. DNA replication in the archaea. Microbiol. Mol. Biol. Rev., 2006, 70, 876-87.

[2] Kelman, L.M.; Kelman, Z. Archaea: an archetype for replication initiation studies? Mol. Microbiol., 2003, 48, 605-15.

[3] Neuwald, A.F.; Aravind, L.; Spouge, J.L.; Koonin, E.V. AAA+: A class of chaperone-like ATPases associated with the assembly, operation, and disassembly of protein complexes. Genome Res., 1999, 9, 27-43.

[4] Dueber, E.L.; Corn, J.E.; Bell, S.D.; Berger, J.M. Replication origin recognition and deformation by a heterodimeric archaeal Orc1 complex. Science, 2007, 317, 1210-3.

[5] Gaudier, M.; Schuwirth, B.S.; Westcott, S.L.; Wigley, D.B. Structural basis of DNA replication origin recognition by an ORC protein. Science, 2007, 317, 1213-6.

[6] Liu, J.; Smith, C.L.; DeRyckere, D.; DeAngelis, K.; Martin, G.S.; Berger, J.M. Structure and function of Cdc6/Cdc18: implications for origin recognition and checkpoint control. Mol. Cell, 2000, 6, $637-48$.
[7] Singleton, M.R.; Morales, R.; Grainge, I.; Cook, N.; Isupov, M.N.; Wigley, D.B. Conformational changes induced by nucleotide binding in Cdc6/ORC from Aeropyrum pernix. J. Mol. Biol., 2004, 343, 547-57.

[8] Lee, D.G.; Bell, S.P. ATPase switches controlling DNA replication initiation. Curr. Opin. Cell Biol., 2000, 12, 280-5.

[9] Grabowski, B.; Kelman, Z. Autophosphorylation of archaeal Cdc6 homologues is regulated by DNA. J. Bacteriol., 2001, 183, 545964.

[10] Grainge, I.; Gaudier, M.; Schuwirth, B.S.; Westcott, S.L.; Sandall, J.; Atanassova, N.; Wigley, D. B. Biochemical analysis of a DNA replication origin in the archaeon Aeropyrum pernix. J. Mol. Biol., 2006, 363, 355-69.

[11] Haugland, G.T.; Shin, J.H.; Birkeland, N.K.; Kelman, Z. Stimulation of MCM helicase activity by a Cdc6 protein in the archaeon Thermoplasma acidophilum. Nucleic Acids Res., 2006, 34, 63376344.

[12] Haugland, G.; Sakakibara, N.; Pey, A.; Rollor, C.; Birkeland, N.; Kelman, Z. Thermoplasma acidophilum Cdc6 protein stimulates MCM helicase activity by regulating its ATPase activity. Nucleic Acids Res., 2008, in press.

[13] Studier, F. W. Protein production by auto-induction in high density shaking cultures. Protein Expr. Purif., 2005, 41, 207-34.

[14] Schuck, P. Size-distribution analysis of macromolecules by sedimentation velocity ultracentrifugation and lamm equation modeling. Biophys. J., 2000, 78, 1606-19. 
[15] Abramoff, M.; Magelhaes, P.; Ram, S. Image Processing with ImageJ. Biophotonics Int., 2004, 11, 36-42.

[16] Guex, N.; Peitsch, M.C. SWISS-MODEL and the SwissPdbViewer: an environment for comparative protein modeling. Electrophoresis, 1997, 18, 2714-23.

[17] Schwede, T.; Kopp, J.; Guex, N.; Peitsch, M.C. SWISS-MODEL: An automated protein homology-modeling server. Nucleic Acids Res., 2003, 31, 3381-5.

[18] Chenna, R.; Sugawara, H.; Koike, T.; Lopez, R.; Gibson, T.J.; Higgins, D.G.; Thompson, J.D. Multiple sequence alignment with the Clustal series of programs. Nucleic Acids Res., 2003, 31, 3497500 .

[19] Arnold, K.; Bordoli, L.; Kopp, J.; Schwede, T. The SWISSMODEL workspace: a web-based environment for protein structure homology modelling. Bioinformatics., 2006, 22, 195-201.

[20] Richter, W. Determining the subunit structure of phosphodiesterases using gel filtration and sucrose density gradient centrifugation. Methods Mol. Biol., 2005, 307, 167-80.

[21] De Felice, M.; Esposito, L.; Pucci, B.; Carpentieri, F.; De Falco, M.; Rossi, M.; Pisani, F.M. Biochemical characterization of a CDC6-like protein from the crenarchaeon Sulfolobus solfataricus. J. Biol. Chem., 2003, 278, 46424-31.

[22] De Felice, M.; Esposito, L.; Pucci, B.; De Falco, M.; Manco, G.; Rossi, M.; Pisani, F.M. Modular organization of a Cdc6-like protein from the crenarchaeon Sulfolobus solfataricus. Biochem. J., 2004, 381, 645-53.
[23] De Felice, M.; Esposito, L.; Rossi, M.; Pisani, F.M. Biochemical characterization of two Cdc6/ORC1-like proteins from the crenarchaeon Sulfolobus solfataricus. Extremophiles, 2006, 10, 61-70.

[24] Matsunaga, F.; Forterre, P.; Ishino, Y.; Myllykallio, H. In vivo interactions of archaeal Cdc6/Orc1 and minichromosome maintenance proteins with the replication origin. Proc. Natl. Acad. Sci. USA, 2001, 98, 11152-7.

[25] Fröls, S.; Gordon, P.; Panlilio, M.; Duggin, I.; Bell, S.; Sensen, C.; Schleper, C. Response of the hyperthermophilic archaeon Sulfolobus solfataricus to UV damage. J. Bacteriol., 2007, 2007, 23.

[26] Götz, D.; Paytubi, S.; Munro, S.; Lundgren, M.; Bernander, R.; White, M. Responses of hyperthermophilic crenarchaea to UV irradiation. Genome Biol., 2007, 8, R220.

[27] Weinreich, M.; Liang, C.; Stillman, B. The Cdc6p nucleotidebinding motif is required for loading $\mathrm{mcm}$ proteins onto chromatin. Proc. Natl. Acad. Sci. USA, 1999, 96, 441-6.

[28] Kasiviswanathan, R.; Shin, J.H.; Kelman, Z. Interactions between the archaeal Cdc6 and MCM proteins modulate their biochemical properties. Nucleic Acids Res., 2005, 33, 4940-50.

[29] Kelman, Z.; White, M.F. Archaeal DNA replication and repair. Curr. Opin. Microbiol., 2005, 8, 669-76.

[30] Giraldo, R. Common domains in the initiators of DNA replication in Bacteria, Archaea and Eukarya: combined structural, functional and phylogenetic perspectives. FEMS Microbiol. Rev., 2003, 26, 533-54.

() Haugland et al.; Licensee Bentham Open.

This is an open access article licensed under the terms of the Creative Commons Attribution Non-Commercial License (http://creativecommons.org/licenses/by-nc/3.0/) which permits unrestricted, non-commercial use, distribution and reproduction in any medium, provided the work is properly cited. 